Accepted refereed manuscript of: Redpath S, Keane A, Andren H, Baynham-Herd Z, Bunnefeld N, Duthie AB, Frank J, Garcia CA, Mansson J, Nilsson L, Pollard CRJ, Rakotonarivo OS, Salk CF \& Travers H (2018) Games as Tools to Address Conservation Conflicts, Trends in Ecology and Evolution, 33 (6), pp. 415-426. DOI: https://doi.org/10.1016/j.tree.2018.03.005

(C) 2018, Elsevier. Licensed under the Creative Commons Attribution-NonCommercial-NoDerivatives 4.0 International http://creativecommons.org/licenses/by-nc-nd/4.0/

\title{
1 Games as tools to address conservation conflicts
}

Steve M. Redpath ${ }^{1,3^{*}}$, Aidan Keane ${ }^{2}$, Henrik Andrén ${ }^{3}$, Zac Baynham-Herd ${ }^{2}$, Nils Bunnefeld ${ }^{4}$, A. Bradley Duthie ${ }^{4}$, Jens Frank ${ }^{3}$, Claude A. Garcia ${ }^{5,6}$, Johan Månsson ${ }^{3}$, Lovisa Nilsson ${ }^{3}$, Chris R. J. Pollard ${ }^{4}$, O. Sarobidy Rakotonarivo ${ }^{4}$, Carl F. Salk7, Henry Travers $^{8}$

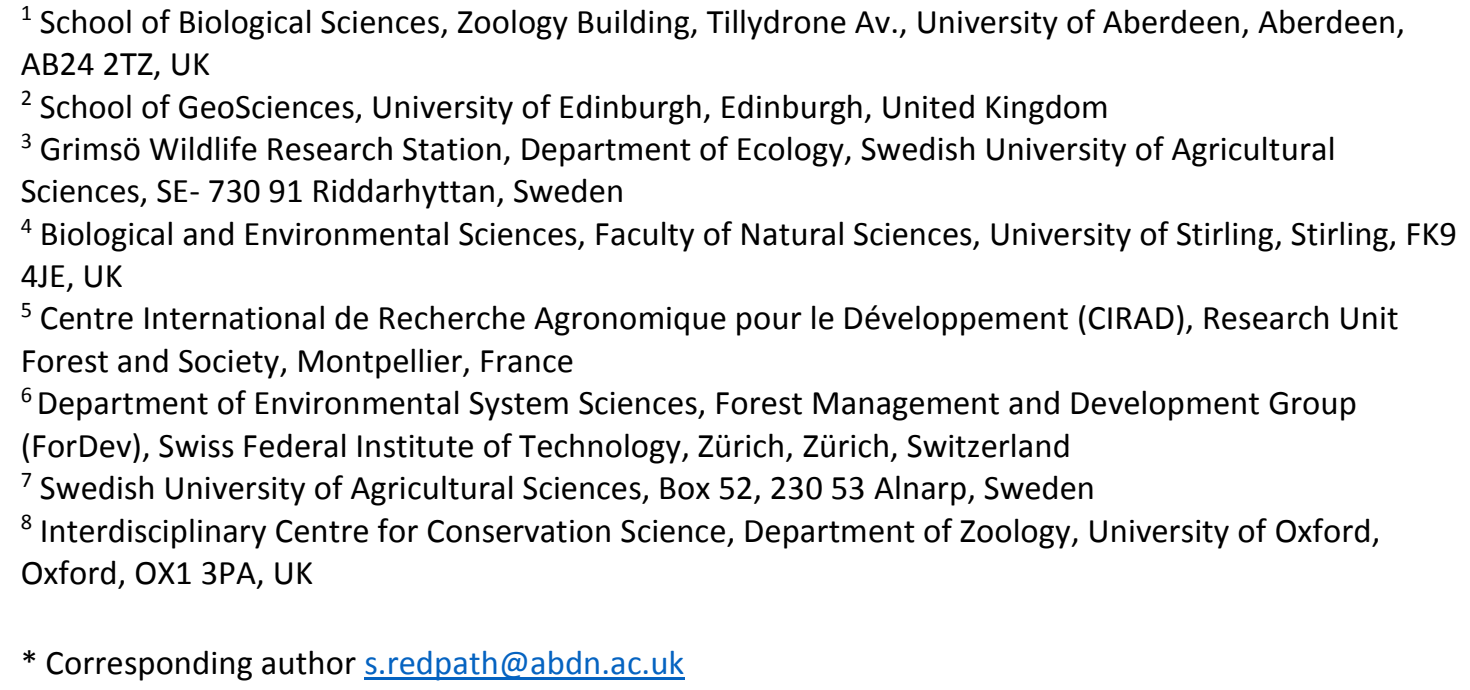

\section{Keywords}

Conservation; conflicts; game theory; experimental games; constructivist games; role-playing.

Highlights (two to four)

See conflict games highlights.doc

Abstract (100 - 120 words) challenging to study. We explore the utility of theoretical, experimental and constructivist approaches to games to help understand and manage these challenges. We show how these approaches can help develop theory, understand patterns in conflict and highlight potentially effective management solutions. The choice of approach should be guided by the research question and whether the focus is on testing hypotheses, predicting behaviour or engaging stakeholders. Games provide an exciting opportunity to help unravel the complexity in conflicts, whilst researchers need an awareness of the limitations and ethical constraints involved. Given the opportunities, this field will benefit from greater investment and development. 


\section{The conflict challenge}

50

Conflicts are widespread within conservation and are damaging to both conservation interests and to the livelihoods and well-being of people involved [1,2]. Such conflicts are often complex, seemingly intractable and open-ended "wicked" problems [3-5]. Whilst superficially they may appear to be about lions attacking livestock, or the impact of superabundant geese in an agricultural landscape, in reality they involve complex layers of multiple stakeholders with different interests, values, goals, and life experiences in different political, cultural and historical settings [2,6-9]. The complexity of conflicts challenges our ability to tease out critical elements, understand the dynamics of conflict and stakeholder behaviour, design effective interventions, understand how to promote engagement and build possible solutions. Traditional ecological approaches to studying such issues have often failed to meet this challenge and in some cases have led to ineffective interventions which at worst can exacerbate existing problems [10]. understand conflicts and their management. In everyday usage, a game is a competitive activity defined by its rules, and is generally played for fun. However, a more formal definition is offered by game theory, which regards a game as a model of a strategic situation in which the outcome of an individual's action also depends on the actions chosen by others[11,12]. Viewed in this way, games provide both a

71 framework for formal analysis of conflicts and form the basis of a set of powerful 
73 the beliefs and behaviour of the participants, examine the effects of changes to the

74 system and engage stakeholders in productive discussion.

75

Various approaches to studying conflict and co-operation based on games have been developed in fields related to conservation (e.g. natural resource management [13, 15,1617 ]; cooperation over the provision of public goods [14]), but the games literature can seem a bit overwhelming: the characteristics, strengths and weakness of alternative approaches are not always clearly understood; they have different philosophical underpinnings; and the terminology used to describe them can be confusing for non-specialists. As a result, they have not yet been widely applied to the study of conservation conflicts.

85

We cannot hope to be comprehensive in reviewing the diversity of games here, so instead we focus on describing and differentiating between theoretical, experimental and constructivist approaches to using games that are relevant to those working in conservation. We explore how each one may contribute to our understanding and management of conflict. We start by briefly describing and illustrating the approaches with examples. We then consider the types of problems that emerge in conflict situations and how they may be addressed by the different approaches to games. We then examine an on-going conflict to illustrate how games may help to understand and manage it. Lastly, we consider some of the general limitations and ethical issues involved in using games in conflicts and propose promising directions for future work. 


\section{Approaches to games}

Theoretical games are characterised by a formal mathematical analysis or simulation of players, behaviours, outcomes and rules (see Box 1). They are useful for understanding the nature of conflicts and identifying novel solutions to real-world situations of strategic conflict. For example, a typical situation concerns the joint goals of wildlife conservation and food production where protected animals have a negative impact on farmers. Such a scenario could be simplified to consider two possible strategies - for parties to cooperate, or to defect as when farmers illegally hunt or conservationists exclude local people from the benefits of tourism income. Game-theoretic analyses of such simple scenarios often seek analytic solutions [13]. For example, in the "tragedy of the commons" scenario [14], individuals seek to maximise their own payoffs, leading to long term reductions in benefits for everyone (all wild animals killed and no income from tourism). Because this problem is defined by strategic interactions among rational players, a game-theoretic perspective can be used to better understand such conflicts and potentially offer novel solutions for promoting cooperation and sustainability $[15,16]$, such as having an agreed level of wild animals, agriculture and income from tourism.

In the related fields of common pool resources, land and water management and fisheries, theoretical games have included more complex dynamic simulations, the coupling of social-ecological systems and the uncertainty that is inherent in these systems. The inclusion of both natural resource dynamics and human behaviour has improved our conceptual understanding of conflict situations [17-19], broken down the complexity of decision-making for individual stakeholder objectives [20], allowed 
121 us to make qualitative or quantitative predictions of behaviour or other system

122 outcomes [21] and unified case studies through common theory [15,22]. Theoretical

123 games typically assume that simulated players follow a particular set of behaviour

124 patterns, such as being rational decision-makers, providing a baseline for comparison

125 with real-world behaviour [12]. However, behaviours deviating from classical

126 economic theory are also possible $[23,24]$. For a detailed discussion of the use of

127 game-theoretic approaches in conservation see [18].

128 Strengths: Useful to probe theoretical understanding of a situation, examine the

129 logical conclusions of assumptions about a conflict, and make predictions about the

130 effects of changing aspects of a system.

131 Weaknesses: Necessarily simplified; they cut humans out of the loop, so the

132 complexity of real people in the process is lost.

134 Experimental games are used to investigate participant behaviour in controlled

135 strategic situations, in either the laboratory or the field [25]. Experiments based on

136 games provide powerful tools for testing theoretical predictions about individual and

137 group behaviour [26] and for quantifying behavioural traits, such as levels of trust

138 and trustworthiness [27] and preferences for risk or fairness [28]. In this way,

139 experimental games enable the investigation of responses to conservation

140 interventions within the context of complex social dilemmas without the need to

141 rely on theoretical assumptions, or expensive full implementation studies. They are

142 well suited to investigations of possible conflict management strategies, enabling

143 researchers to study their relative effectiveness in a controlled setting prior to

144 implementation (See Box 2). This approach is particularly useful when participants in 
145 a game are themselves stakeholders in the conflict the game seeks to model since

146 behaviour has been shown to vary with factors such as cultural and educational

147 background and familiarity with the situation being represented [29]. The application

148 of experimental game approaches with real stakeholders thus increases the

149 likelihood that results of experiments are applicable to real world resources,

150 institutions, and people [26].

151 Strengths: Useful for testing theories and practical interventions that are

152 difficult/expensive to test at 'reality scale' and to quantify behavioural traits.

153 Weaknesses: Necessarily simplified, although not as much as theoretical games;

154 Design and implementation requires attention to detail so that a truly fair

155 comparison is made among treatments. Outcomes can be sensitive to small changes

156 in the experimental design.

158 The constructivist approach requires games to be designed and used in iterative

159 processes to understand conflict situations and to help stakeholders come up with

160 solutions [30]. These games can be card games, board games or role-playing games,

161 and they are used to foster dialogue and build trust among stakeholders [31]. As for

162 experimental games, constructivism integrates players inside the game - bringing in

163 their needs, desires, beliefs and intentions, allowing their behaviour in the game to

164 represent differences in knowledge and values. The difference from other

165 approaches, however, is that here the players are given freedom to explore a range

166 of possible outcomes in strategic situations, so they can reframe the problem and

167 the game, and create new options not initially contemplated by the research team

$168[30]($ Box 3). As a result the capacity to learn and anticipate are integral to the 
behaviour observed within a game [32]. In conservation conflict contexts, these games often have a multi-agent system structure, with a landscape, resources, and stakeholders, interactions within and among these components, and explicit representation given to the cognitive capacities of the agents [33]. This approach is exemplified by the work of the Companion Modelling community

\section{(www.commod.org).}

Strengths: Flexible enough to allow for a wide range of human behaviour; useful to establish dialogue, help people understand different viewpoints and agree a shared understanding of a conflict.

Weaknesses: Documentation, analysis, replication and synthesis are all challenging.

\section{How can games be used to address questions about conflicts?}

A number of issues that emerge from research on conflicts are pertinent to games [2] (Table 1). First, there is a need to find generalities from the numerous case studies and build relevant theory. For example, we might want to develop hypotheses for how cooperation can develop in dynamic ecosystems that typically have a high degree of uncertainty and significant fluctuations in resources [34]. When mapping conflicts, there is a need to explore the underlying patterns and behaviour of conflicts - how they emerge and how they change over time, and when they switch from conflict to cooperation $[35,36]$. In addition, understanding conflict relies on mapping the underlying stakeholder values, emotions, interests and positions and how these aspects affect behaviour in conflicts [37-41]. Moving into conflict management, a widespread issue lies in understanding the impact of different types of interventions on stakeholder behaviour and on the level of 
194 compensation schemes or lethal control, or interventions focused on trust and

195 relationships, dialogue processes, governance and institutions [42-50]. Lastly, a

196 critical issue lies in the importance of dialogue and engagement in promoting

197 listening, understanding and the development of solutions among stakeholders.

199 All three approaches to using games can provide useful insight into each of these

200 areas of conflict research (Table 1), and the choice between them should be guided

201 by the specific research question and context in which they will be applied. However,

202 some approaches tend to suit certain objectives. For example, experimental

203 approaches are well suited to exploring how an intervention might alter stakeholder

204 behaviour in a conflict, whilst constructivist approaches are useful when exploring

205 solutions with stakeholders. It is also worth pointing out that synergies may arise by

206 using combinations of games, such as experimental and constructivist approaches

207 [76].

208 Table 1: Suggestions about how different approaches to games could be used to 209 address objectives relevant to understanding and managing conservation conflicts.

210 These suggestions are illustrative in nature and are not intended to be exhaustive or 211 mutually exclusive. Each suggestion is accompanied by a reference to a study where 212 this type of approach to games was used to address comparable objectives in a 213 related field.

\begin{tabular}{|l|l|l|l|}
\hline & \multicolumn{3}{|c|}{ Approach } \\
\hline Objective & $\begin{array}{c}|c| \\
\text { Theoretical } \\
\text { e.g. game theoretic modelling } \\
\text { on computer }\end{array}$ & $\begin{array}{l}\text { Experimental } \\
\text { e.g. common pool resource and } \\
\text { public goods games in lab and } \\
\text { field }\end{array}$ & $\begin{array}{l}\text { Constructivist } \\
\text { e.g. role playing games and } \\
\text { companion modelling in lab and } \\
\text { field }\end{array}$ \\
\hline $\begin{array}{l}\text { Develop theory } \\
\text { about } \\
\text { conservation } \\
\text { conflict in a } \\
\text { changing } \\
\text { environment }\end{array}$ & $\begin{array}{l}\text { Relevance of approach: } \\
\text { To explore the logical } \\
\text { consequences of theories of } \\
\text { conflict }\end{array}$ & $\begin{array}{l}\text { Relevance of approach: } \\
\text { To test assumptions about } \\
\text { behaviour in conflicts and look } \\
\text { for generalities }\end{array}$ & $\begin{array}{l}\text { Relevance of approach: } \\
\text { To elicit the insights of } \\
\text { stakeholders about the nature } \\
\text { of conflicts }\end{array}$ \\
\hline
\end{tabular}




\begin{tabular}{|c|c|c|c|}
\hline & $\begin{array}{l}\text { Exploring whether social } \\
\text { ostracism can promote } \\
\text { cooperation and sustainability } \\
\text { in fisheries harvesting, } \\
\text { assuming rational agents } \\
\text { [19] (Box 1). }\end{array}$ & $\begin{array}{l}\text { Testing how environmental } \\
\text { stochasticity and trust affect } \\
\text { cooperation to mitigate } \\
\text { climate-change [53]. }\end{array}$ & $\begin{array}{l}\text { Eliciting stakeholders' reported } \\
\text { behavioural strategies in a } \\
\text { natural resource management } \\
\text { and conservation setting [31]. }\end{array}$ \\
\hline $\begin{array}{l}\text { Understand how } \\
\text { conflicts emerge, } \\
\text { evolve and } \\
\text { resolve }\end{array}$ & $\begin{array}{l}\text { Relevance of approach: } \\
\text { To examine the conditions } \\
\text { under which conflicts are likely } \\
\text { and suggest how they might be } \\
\text { changed to encourage } \\
\text { cooperation. } \\
\text { Comparable example: } \\
\text { Analysing the history of } \\
\text { environmental conflict, } \\
\text { identifying the structure and } \\
\text { actions (e.g. enforcement) of } \\
\text { the conflict and predicting } \\
\text { possible solutions [54]. }\end{array}$ & $\begin{array}{l}\text { Comparable example: } \\
\text { Testing the effects of fear and } \\
\text { environmental uncertainty on } \\
\text { co-operation between nations } \\
\text { with respect to climate change } \\
\text { action [56]. }\end{array}$ & $\begin{array}{l}\text { Relevance of approach: } \\
\text { To support dialogue and shared } \\
\text { learning to co-identify the roots } \\
\text { of and solutions to conflict } \\
\text { Comparable example: } \\
\text { Building a shared } \\
\text { representation of farmers' } \\
\text { interactions with a protected } \\
\text { area to allow for the } \\
\text { negotiation of uncertainties and } \\
\text { risks [57]. }\end{array}$ \\
\hline $\begin{array}{l}\text { Understand how } \\
\text { values, interests } \\
\text { and positions } \\
\text { affect stakeholder } \\
\text { behaviour }\end{array}$ & $\begin{array}{l}\text { Relevance of approach: } \\
\text { To predict conflict from values } \\
\text { and norms } \\
\text { Comparable example: } \\
\text { Explaining outputs from } \\
\text { different types of theoretic } \\
\text { games in relation to how } \\
\text { equity, reciprocity and } \\
\text { competitive behaviour affect } \\
\text { co-operation [58]. }\end{array}$ & $\begin{array}{l}\text { Relevance of approach: } \\
\text { To test how individual and } \\
\text { institutional characteristics } \\
\text { affect behaviour } \\
\text { Comparable example: } \\
\text { Investigating how personal } \\
\text { norms and other individual } \\
\text { scale variable in the context of } \\
\text { village-scale influence } \\
\text { cooperative behaviour [61]. }\end{array}$ & $\begin{array}{l}\text { Relevance of approach: } \\
\text { To facilitate understanding of } \\
\text { behaviour and social learning. } \\
\text { Comparable example: } \\
\text { Revealing the processes leading } \\
\text { to overgrazing. The game } \\
\text { facilitated social learning and } \\
\text { game facilitated instrumental } \\
\text { and served as a platform for } \\
\text { sharing views, knowledge, and } \\
\text { perceptions [63] }\end{array}$ \\
\hline $\begin{array}{l}\text { Identify how } \\
\text { interventions } \\
\text { affect stakeholder } \\
\text { behaviour and } \\
\text { conflict }\end{array}$ & $\begin{array}{l}\text { Relevance of approach: } \\
\text { To predict behavioural } \\
\text { responses to different } \\
\text { interventions } \\
\text { Comparable example: } \\
\text { Investigating effects of } \\
\text { payments and sanctions on } \\
\text { poaching and importance of } \\
\text { individual-level heterogeneity } \\
\text { and strategic decision-making } \\
\text { in design of interventions. [67]. }\end{array}$ & $\begin{array}{l}\text { Relevance of approach: } \\
\text { To test behavioural responses } \\
\text { to different interventions } \\
\text { Comparable example: } \\
\text { Assessing three alternative } \\
\text { payment schemes for } \\
\text { promoting sustainable forest } \\
\text { resource use and the effect of } \\
\text { communication, leadership, and } \\
\text { external advice on their } \\
\text { effectiveness [72]. }\end{array}$ & $\begin{array}{l}\text { Relevance of approach: } \\
\text { To explore behavioural } \\
\text { responses to different } \\
\text { interventions with stakeholders } \\
\text { Comparable example: } \\
\text { Revealing the effect of policy } \\
\text { change on stakeholder } \\
\text { behaviour in coffee plantations } \\
\text { (Box } 3 \text { ) }\end{array}$ \\
\hline $\begin{array}{l}\text { Promote } \\
\text { engagement } \\
\text { amongst } \\
\text { stakeholders to } \\
\text { understand } \\
\text { conflicts and } \\
\text { develop solutions. }\end{array}$ & $\begin{array}{l}\text { Relevance of approach: } \\
\text { To co-construct theoretical } \\
\text { models to explore solutions } \\
\text { Comparable example: } \\
\text { Combining theoretical and } \\
\text { role-playing games to simulate } \\
\text { fishery management and } \\
\text { explore effectiveness of } \\
\text { management options [73]. }\end{array}$ & $\begin{array}{l}\text { Relevance of approach: } \\
\text { To promote dialogue and test } \\
\text { solutions } \\
\text { Comparable example: } \\
\text { Using experimental games as a } \\
\text { development tool to teach } \\
\text { communities about incentives } \\
\text { and strategic interaction [74] }\end{array}$ & $\begin{array}{l}\text { Relevance of approach: } \\
\text { To promote and support co- } \\
\text { management } \\
\text { Comparable example: } \\
\text { Bringing local communities and } \\
\text { protected area managers } \\
\text { together to co-design role- } \\
\text { playing game and collaborate to } \\
\text { produce effective management } \\
\text { plans.[57]. }\end{array}$ \\
\hline
\end{tabular}

216 To further guide the choice of approaches, it is useful to ask whether the main aim of

217 the game is to test specific hypotheses, predict behaviour or to engage stakeholders 
218 (Figure 1). Experimental approaches best fit the aim of testing hypotheses, and

219 constructivist approaches are best suited if the aim is engagement. If the aim is to

220 predict future behaviour, then the most appropriate approach will depend on two

221 things: first, whether or not there is a reasonable model of the players' decision-

222 making process, and second, whether the main interest is in the system or the

223 stakeholders. If there is knowledge of how people choose between a small set of

224 actions then theoretical games will be most useful for predicting the behaviour of

225 both systems and stakeholders. However, if there is no reasonable model of

226 decision-making, then constructivist approaches are likely to be most helpful at

227 predicting system behaviour, and experimental games are likely to be most helpful

228 at predicting stakeholder behaviour.

230 Figure 1. Decision tree highlighting how different approaches to games (theoretical, 231 experimental and constructivist) fit the different objectives outlined in table 1, and 232 whether the aim of the research is focused on testing hypotheses, predicting future 233 behaviour or stakeholder engagement.

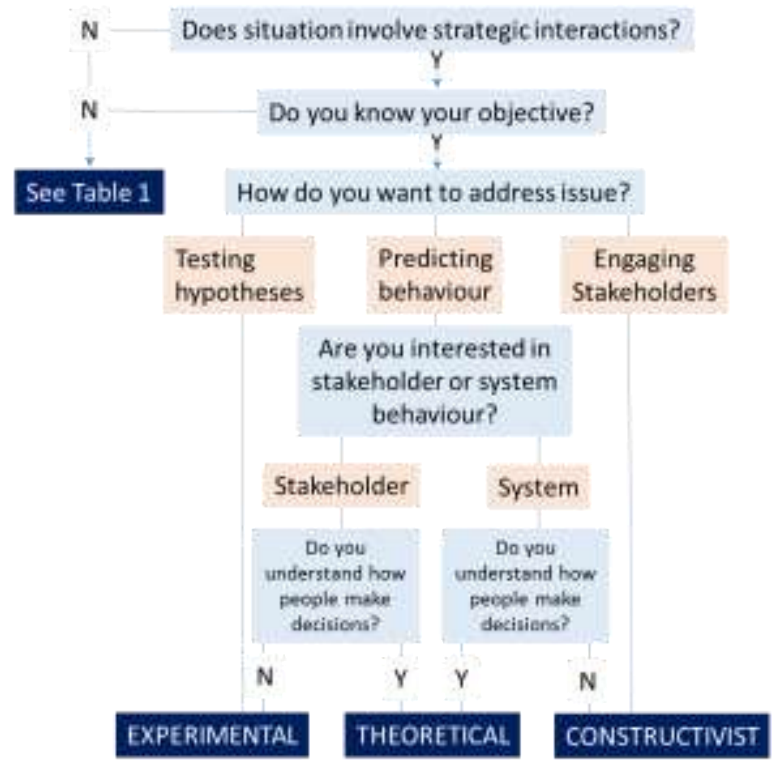


238 To illustrate the utility of alternative approaches, we consider how games could be

239 used to illuminate different facets of the conflict over rapidly increasing geese

240 populations (Box 4). Most populations of geese in Europe (14 of 17 populations of 7

241 species) have grown from threatened to super-abundant over the last 60 years [77].

242 These geese often graze in intensively managed agricultural fields leading to conflict

243 with farming objectives [78,79]. Management strategies and policies have failed to

244 adapt to this increasing problem, causing frustration among stakeholders, and

245 reinforcing polarisation and conflicts [80]. Games can provide insight into the

246 understanding and management of this conflict in several ways.

248 General limitations \& ethics

249 Whilst games have enormous potential to provide insight, they are not a panacea.

250 One of the main limitations of all the games is that, as for all models of reality, they

251 require complex situations to be simplified. It is hard to choose which aspects of a

252 situation can be safely ignored in order to develop an appropriate game. In addition,

253 games may give the illusion of representing real-world outcomes, yet they cannot

254 predict with certainty what will happen when the stakes are real. A particular

255 concern about the external validity arises in situations where the payoffs used in a

256 game are considerably lower than in real-life [26,81]. Similarly, there are issues of

257 internal validity - are the decisions being made by game participants the same as

258 those a researcher believes are being made? [81]. These questions need to be

259 considered throughout the process of developing, implementing and interpreting a 
game. Debriefing session after experimental/constructivist games with the

261 participants are valuable in helping to provide insight into their behaviour.

263 While a game can seem innocuous fun, games with stakeholders can raise serious

264 ethical issues: from framing and game design through implementation and

265 publishing the results. For example, at the design stage, it is easy for researchers to

266 plan a game in such a way that their preferred solution is the winning strategy,

267 turning the outcome of the game into a foregone conclusion. To avoid this pitfall, the

268 community of Companion Modelling has drafted a charter of conduct [30]. In

269 addition, early and thorough testing are essential to address questions such as, "are

270 participants able to understand the game and participate meaningfully given their

271 level of education and cultural background?", or "are we in a position to understand

272 what participants take from the game?". Game designers need to consider how to

273 capture and represent sensitive behaviours, such as corruption, poaching or

274 reprisals. Designs and tools are available to avoid revealing individual information to

275 other players, or even to the research team [71]. Stakeholders may also question

276 whether games are serious enough to warrant the interest of busy professionals

277 with a reputation to lose [32].

279 Payments involving cash or other tangible goods are sometimes used in games

$280[71,82]$. These approaches need to be thought through before implementation.

281 Payments linked to individual performance within games are supposed to give

282 players an incentive to focus harder, but also incentivise acting more selfishly,

283 potentially undermining the basis of collaboration [83]. In certain contexts, this 
284 would improve understanding of the system. In others, it could be detrimental,

285 particularly if the incentives are trivial compared to the costs that stakeholders incur

286 in real life.

288 During certain games, the role of the participants will evolve, and researchers need

289 to reflect on how much power they are willing to give to participants and how to

290 deal with the power asymmetries among stakeholders and between stakeholders

291 and the research team [84]. In fact, even playing a game may affect the system, so

292 researchers need to exercise reflexivity to be aware of any potential unintended

293 outcomes of such interventions [85]. It is worth noting that although games with

294 participants can spark conflicts or add fuel to existing ones, conflicts are rarely

295 created by the interactions in the games but are inherent to the situation being

296 explored. Games simply bring these processes to light so that the conflict can be

297 managed instead of being suppressed by the power structure of the status quo [86].

298 Nevertheless, they require careful facilitation to manage expectations and deal with

299 emerging issues.

301 The ethical considerations of publishing games that involve stakeholders are also

302 important. Participants should be informed how data will be used, who will have

303 access to it, and in what form, particularly if it is identifiable to a particular player. As

304 with other empirical approaches to investigating sensitive behaviour, anonymising

305 individual behaviour may not, in itself, be sufficient to ensure that game participants

306 are protected from harm [87]. 


\section{Future Directions}

309 Games offer exciting opportunities to help guide the understanding and

310 management of conflicts over biodiversity and conservation. This field of conflict

311 research is focused on case studies with limited efforts to draw out the generalities

312 [88]. Games have the potential to help find and explore the generalities, such as the

313 consistent findings in ultimatum games of concern for others - as opposed to the

314 pure self-interest that is often assumed [11], and consider how they might fit in

315 different contexts. We consider a number of outstanding questions in Table 2.

317 Concluding remarks

318 Conflicts are ubiquitous, persistent and damaging. Their complexity and critical

319 human dimensions mean that they are challenging to study and manage. Games

320 have the potential to address these problems and provide genuine insight into a

321 wide range of issues around how we understand and manage conflicts. Moreover,

322 games also have the potential to be fun. There are different types of games available

323 to address different questions and situations - from theoretical games to ones

324 involving the active participation of stakeholders. Given their potential to help

325 develop theory, understand patterns in conflict and highlight potentially effective

326 management solutions, we suggest this field is ripe for development, given proper

327 awareness of the limitations and ethical constraints. 
Box 1 An example of a theoretical game developed to address a fisheries conflict and

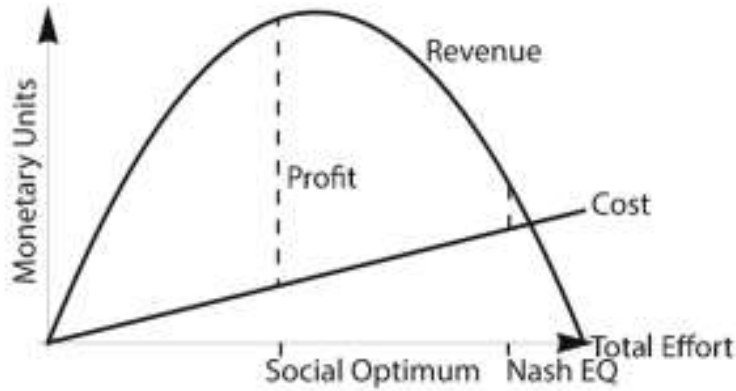

Figure 1 from [19] showing that cooperation and ultimately sustainability is best promoted at a higher total effort of harvest (Nash EQ) than would be optimal (Social Optimum) for maximising long-term profit (dashed lines). Figure reproduced with permission from the journal.

Tilman et al. [19] recently investigated conflict within a social-ecological fishery system by constructing a mathematical model of the fishery as a common-pool resource system. Fishers can increase their own profits by maximising their catch, but the individual gain achieved by doing so contributes to long-term depletion of total fisheries stock. The authors looked at this case study using game theory, defining a 'socially-optimal' fishing strategy that could be enforced by allowing fishers to ostracise one another when over-harvesting occurs. In the mathematical model, fishers could either join a cooperative or they could harvest independently which increased profit, but came at the cost of being ostracised by the cooperative. Further, the punitive power of the cooperative increased with its size, and ostracising independent harvesters also incurred a cost to the fishers in the cooperative.

Tilman et al. [19] modelled the dynamics of fish biomass and the fraction of fishers that joined the cooperative. Fishers were assumed to be rational agents who joined or not based on whichever choice maximised their profit. They demonstrated the conceptually general, counter-intuitive result that social ostracism can promote cooperation and ultimately sustainability when individuals within a cooperative harvest at a rate that is higher than what would otherwise be optimal for maximising the long-term rate of resource harvest overall. This is because a higher harvest rate for individuals within a cooperative can discourage independent harvesters from invading, and ultimately leads to more sustainable long-term harvests. Hence, this theoretical approach suggested a novel, generally applicable, way to address 
Box 2. An example of an experimental game developed to predict the outcomes of incentive-based interventions on illegal resource use in Cambodia.
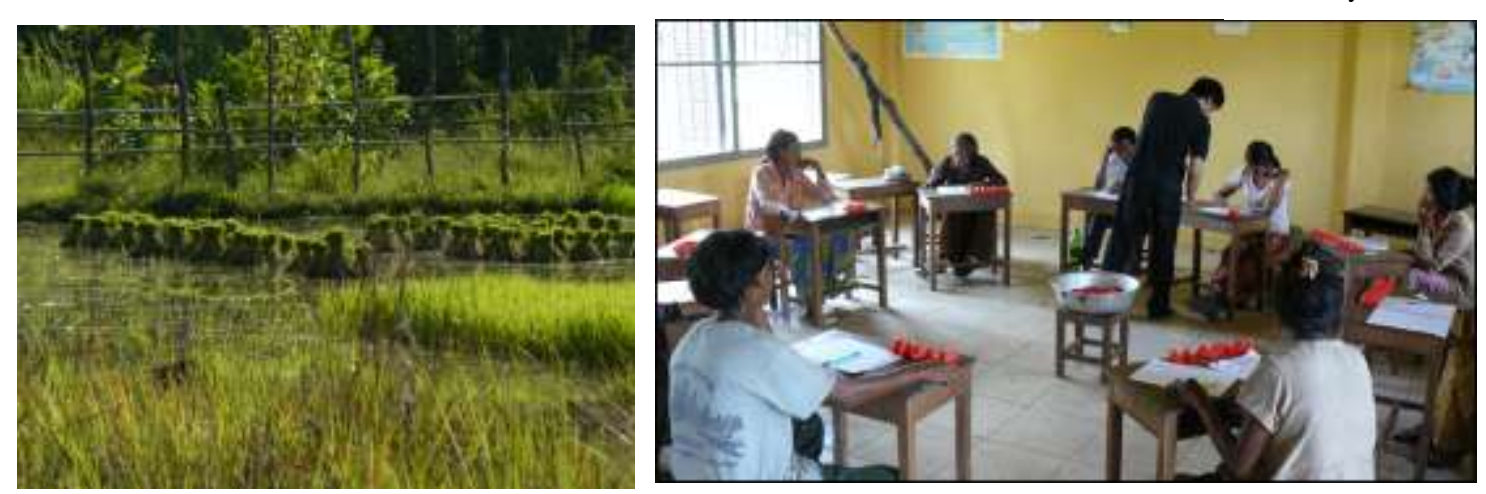

In Cambodia, illegal resource use inside protected areas is common, with high rates of hunting and land clearance in particular leading to conflict between local people and conservation authorities. One solution that has been developed to mitigate this conflict is the introduction of incentive-based interventions to promote compliance with land use and resource access zones. To evaluate the potential behavioural impact of these interventions, Travers et al. [70] used an experimental game adapted from the common-pool resource game developed by Ostrom et al. [15]. To aid understanding, the game was framed around the harvesting of fish from a pond within the protected area. Each participant was given the option of harvesting fish from this pond or choosing to leave fish unharvested for future use. Payoffs were set such that harvested fish were worth considerably more to the individual harvesting than if they had been left in the pond. However, the collective value of fish left in the pond was greater than the payoff an individual received from harvesting. This set up a social dilemma in which the optimum strategy for players who wanted to maximise their own payoff was to harvest as many fish as they could, whereas the social optimum was to leave all fish in the pond.

A number of alternative management strategies were investigated, including fines if participants were caught harvesting too many fish and individual or collective rewards for keeping harvests within predefined thresholds. The most effective interventions at reducing fish harvest were those that encouraged participants to self-organise, through the use of incentives that were conditional on group behaviour or allocated to individuals by the group. Although the treatments considered in the game were stylised versions of those applied in reality, the findings provided valuable insight into the features of incentive initiatives predicted to have the greatest impact on encouraging sustainable use of resources and mitigating conflict between local people and conservation authorities. This has led to increased efforts to promote the development of local institutions and the provision of collective incentives to local communities. 


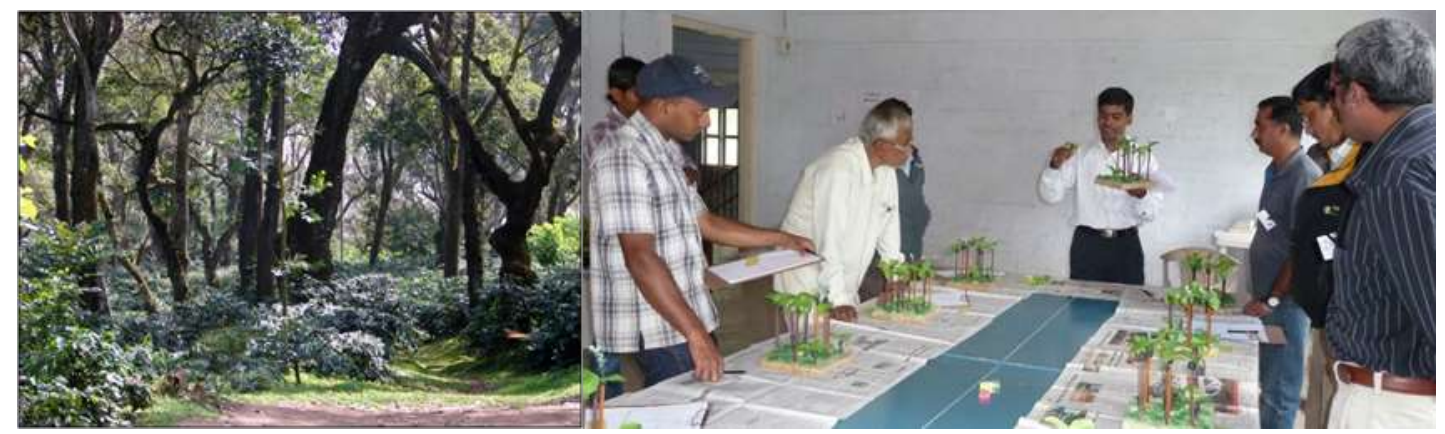

The landscape of Kodagu, in India's Western Ghats is a mosaic of rice fields, forest fragments and coffee farms. Coffee is produced under complex, multi-storeyed agroforestry systems, but farmers are replacing a diverse, native canopy cover with the fast growing, introduced Silver Oak Grevillea robusta $[89,90]$. Whereas the harvesting of native species is controlled, silver oak can be logged and traded [91]. For years, coffee farmers and their representatives have been demanding full ownership rights over trees on their land [89]. These demands have been opposed by the Forest Department for fear of the environmental impact. Farmer representatives have denied that the granting of rights would result in a loss of tree cover or conversion [92]. This polarized debate has led to a long-lasting standoff.

A role-playing game was developed with academics, representatives of the Central Coffee Board of India, local conservation organisations, private coffee trading companies, and community leaders in eight separate workshops across the district. Through workshops and interviews, the game was co-constructed and explored two scenarios. The business as usual scenario had rules for selling native trees mimicking the restrictions in place. The tree rights scenario saw these restrictions lifted. These game sessions were recorded and used as a basis for discussion.

The results suggested that farmers would increase their income were they to receive full rights. But we also observed that in such situations they decided to hasten, rather than reverse, the conversion to Silver Oak. This strategy was contrary to expectations that farmers would retain native forest, but instead, the faster rotation of Silver Oak trumped the multiple values of the native trees.

The lessons from this role-play game were bittersweet. The game revealed system components and processes that had been identified in none of the policy narratives of the concerned parties. These represented hidden pitfalls that would have plunged the system into a non-desired state had the current policy change been implemented as initially designed. However, these lessons could not be transferred to the policy process, in part because the findings undermined the initial position of our main partners, the coffee farmers themselves. 

conflict over geese impacts on agricultural systems in Sweden.

Background. Increasing numbers of protected geese in Europe are causing impacts on agricultural production [77]. In Sweden, the government pays compensation and supports the scaring of most goose species, but as populations increase, farmers are asking for more lethal control.

Theoretical game example. Objective - predict the impact of management strategies on collaborations and goose populations. First, map the time series of goose numbers, management actions and players' interactions over time, to develop a modelling framework within which game theory can be applied. Then simulate the actions and players' interactions using mathematical or computational techniques to find actions that reduce conflict. Such a game could enable predictions as to which actions will lead to collaboration and a sustainable goose population under changing conditions of governmental budget changes.

Experimental game example. Objective - test a hypothesis that farmers are more likely to cooperate in a goose management scheme, which uses a lethal rather than non-lethal control method. The game setting would be an idealised landscape in which geese move among farms and damage crops. Players would be farmers who choose between lethal or non-lethal measures using a cash endowment they receive in each round. These measures would only be effective if the sum of investments reached a predetermined threshold. If too few invest, no protection would be achieved. Such an approach would allow researchers to test players' willingness to participate in different measures and examine the effect of collective discussions on individual decision-making. Post-game debriefing sessions would provide a greater understanding of the factors influencing farmer behaviour.

Constructivist games example. Objective - engage stakeholders to explore lethal vs. non-lethal interventions under changing economic resources. This game would be played over a co-developed idealised landscape. Stakeholders would build and play the game to explore the strategies they would employ under lethal and non-lethal action scenarios, interacting with each other and the resources in the landscape. The game would allow the compatibility and sustainability of actions over space and time to be assessed. The design and gaming process and post-game reflections would facilitate a shared understanding of the conflict among participants, enabling an explorations of the outcomes and stakeholder acceptance for measures and the development of innovative interventions. 


\section{Acknowledgements}

512 SR is grateful for the King Carl XVI Gustaf guest professorship that funded the

513 workshop and allowed him to write this paper. We thank the Swedish EPA for 514 supporting JF, LN and JM.

\section{References}

5181 Dickman, A.J. Complexities of conflict: The importance of considering social

519 factors for effectively resolving human-wildlife conflict. , Animal Conservation, $520 \quad$ 13. $(2010), 458-466$

5212 Redpath, S.M. et al. (2013) Understanding and managing conservation 522 conflicts. Trends Ecol. Evol. 28, 100-109

5233 Head, B.W. (2008) Wicked Problems in Public Policy. Public Policy 3, 101-118

5244 Weber, E.P. and Khademian, A.M. (2008) Wicked problems, knowledge 525 challenges, and collaborative capacity builders in network settings. Public Adm. Rev. 68, 334-349

5275 DeFries, R. and Nagendra, H. (2017) Ecosystem management as a wicked 528 problem. Science (80-. ). 356,

$5296 \quad$ Kreuter, M.W. et al. (2004) Understanding Wicked Problems: A Key to 530 Advancing Environmental Health Promotion. Heal. Educ. Behav. 31, 441-454

5317 Madden, F. and McQuinn, B. (2014) Conservation's blind spot: The case for 532 conflict transformation in wildlife conservation. Biol. Conserv. 178, 97-106

5338 Speelman, E.N. et al. (2014) Gaming for smallholder participation in the design 534 of more sustainable agricultural landscapes. Agric. Syst. 126, 62-75

5359 Kronenburg García, A. (2017) Exploring the "layeredness" of recurring natural 536 resource conflicts: The role of Loita Maasai leadership in the Naimina Enkiyio $537 \quad$ Forest conflicts in Kenya. Land use policy 65, 66-77

53810 Bulte, E. and Rondeau, D. (2007) Compensation for wildlife damages: Habitat 539 conversion, species preservation and local welfare. J. Environ. Econ. Manage.

$540 \quad 54,311-322$

54111 Camerer, C.F. (2003) Behavioral Game Theory: Experiments in Strategic 542 Interaction, 
54312 Roger B. Myerson (2013) Game Theory: Analysis of Conflict, Harvard University $544 \quad$ Press.

54513 Adami, C. et al. Evolutionary game theory using agent-based methods. , $546 \quad$ Physics of Life Reviews, 19. (2016) , 1-26

54714 Hardin, G. (1968) The Tragedy of the Commons. Science (80-. ). 162, 1243$548 \quad 1248$

54915 Ostrom, E. et al. Rules, Games, and Common-Pool Resource Problems. , Rules, $550 \quad$ Games, and Common-Pool Resources. (1994) , 3-21

55116 Diekert, F.K. (2012) The tragedy of the commons from a game-theoretic 552 perspective. Sustainability 4, 1776-1786

55317 Frank, D.M. and Sarkar, S. (2010) Group decisions in biodiversity conservation: $554 \quad$ Implications from game theory. PLoS One 5,

55518 Colyvan, M. et al. (2011) The conservation game. Biol. Conserv. 144, 1246$556 \quad 1253$

55719 Tilman, A.R. et al. (2017) Maintaining cooperation in social-ecological

558 systems:: Effective bottom-up management often requires sub-optimal

559 resource use. Theor. Ecol. 10, 155-165

56020 Lee, C.S. (2012) Multi-objective game-theory models for conflict analysis in 561 reservoir watershed management. Chemosphere 87, 608-613

56221 Tesfatsion, L. et al. (2017) An agent-based platform for the study of

563 watersheds as coupled natural and human systems. Environ. Model. Softw. 89, $564 \quad 40-60$

56522 Stewart, A.J. and Plotkin, J.B. (2014) Collapse of cooperation in evolving 566 games. Proc. Natl. Acad. Sci. 111, 17558-17563

56723 Rand, D.G. et al. (2013) Evolution of fairness in the one-shot anonymous $568 \quad$ Ultimatum Game. Proc. Natl. Acad. Sci. 110, 2581-2586

56924 Groeneveld, J. et al. (2017) Theoretical foundations of human decision-making 570 in agent-based land use models - A review. Environ. Model. Softw. 87, 39-48

57125 Harrison, G.W. and List, J.A. (2004) Field Experiments. J. Econ. Lit. 42, 1009$572 \quad 1055$

57326 Levitt, S.D. and List, J.A. (2007) What Do Laboratory Experiments Measuring 574 Social Preferences Reveal About the Real World? J. Econ. Perspect. 21, 153- 
27 Johnson, N.D. and Mislin, A.A. (2011) Trust games: A meta-analysis. J. Econ. Psychol. 32, 865-889

28 Whitt, S. and Wilson, R.K. (2007) The dictator game, fairness and ethnicity in postwar Bosnia. Am. J. Pol. Sci. 51, 655-668

29 Henrich, J. et al. Most people are not WEIRD. , Nature, 466. (2010) , 29

30 Daré, W. et al. (2014) Companion Modelling: A Method of Adaptive and Participatory Research. In Companion Modelling pp. 13-40

31 Le Page, C. et al. (2016) Exploring How Knowledge and Communication Influence Natural Resources Management With REHAB. Simul. Gaming 47, $257-284$

32 Garcia, C. et al. (2016) Learning begins when the game is over. Using games to embrace complexity in natural resources management. GAIA 25, 289-291

33 Ferber, J. (1999) Multi-agent systems : an introduction to distributed artificial intelligence,

34 Laurent-Lucchetti, J., Leroux, J. and Bernard, S.D. (2013) Haggling on the Verge of Disaster. In Analyzing Global Environmental Issues: Theoretical and Experimental Applications and their Policy Implications (A. Dinar \& A. Rappoport, ed), pp. 129-144, Routledge New York and London

35 Cadoret, A. (2009) Conflict dynamics in coastal zones: A perspective using the example of Languedoc-Rousillon (France). J. Coast. Conserv. 13, 151-163

36 Margalida, A. et al. (2014) Vultures vs livestock: conservation relationships in an emerging conflict between humans and wildlife. 48, 172-176

37 Ives, C.D. and Kendal, D. The role of social values in the management of ecological systems. , Journal of Environmental Management, 144. (2014) ,6772

38 Estévez, R.A. et al. (2015) Clarifying values, risk perceptions, and attitudes to resolve or avoid social conflicts in invasive species management. Conserv. Biol. 29, 19-30

39 Lute, M.L. et al. (2016) Moral dimensions of human-wildlife conflict. Conserv. Biol. 30, 1200-1211

40 Nelson, M.P. et al. (2016) Emotions and the Ethics of Consequence in 
60841 Johansson, M. et al. Targeting human fear of large carnivores - Many ideas

609 but few known effects. , Biological Conservation, 201. (2016) , 261-269

61042 Dickman, A.J. (2010) Complexities of conflict: the importance of considering 611 social factors for effectively resolving human-wildlife conflict. Anim. Conserv.

$612 \quad 13,458-466$

61343 Sayer, J. et al. (2013) Ten principles for a landscape approach to reconciling 614 agriculture, conservation, and other competing land uses. Proc. Natl. Acad. 615 Sci. $110,8349-8356$

61644 Bennett, N.J. and Dearden, P. (2014) Why local people do not support 617 conservation: Community perceptions of marine protected area livelihood 618 impacts, governance and management in Thailand. Mar. Policy 44, 107-116

61945 McManus, J.S. et al. (2015) Dead or alive? Comparing costs and benefits of 620 lethal and non-lethal human-wildlife conflict mitigation on livestock farms. $621 \quad$ Oryx 49, 687-695

62246 Sjölander-Lindqvist, A. et al. (2015) Individual and collective responses to large 623 carnivore management: the roles of trust, representation, knowledge spheres, 624 communication and leadership. Wildlife Biol. 21, 175-185

62547 Larson, L. et al. (2016) Human-wildlife conflict, conservation attitudes, and a 626 potential role for citizen science in Sierra Leone, Africa. Conserv. Soc. 14, 205 62748 Pant, G. et al. (2016) Nature and extent of human-elephant Elephas maximus conflict in central Nepal. Oryx 50, 724-731

62949 Salerno, J. et al. (2016) Household livelihoods and conflict with wildlife in 630 community-based conservation areas across northern Tanzania. Oryx 50, 702$631 \quad 712$

63250 Ravenelle, J. and Nyhus, P.J. (2017) Global patterns and trends in human633 wildlife conflict compensation. Conserv. Biol. DOI: 10.1111/cobi.12948

63451 Blanco, E. et al. (2016) The Opportunity Costs of Conservation with 635 Deterministic and Probabilistic Degradation Externalities. Environ. Resour. $636 \quad$ Econ. 64, 255-273

63752 Milinski, M. et al. (2002) Reputation helps solve the "tragedy of the 638 commons." Nature 415, 424-426 
63953 Hasson, R. et al. (2010) Climate change in a public goods game: Investment

640 decision in mitigation versus adaptation. Ecol. Econ. 70, 331-338

64154 Madani, K. and Lund, J.R. (2012) California's Sacramento-San Joaquin Delta

642 Conflict: From Cooperation to Chicken. J. Water Resour. Plan. Manag. 138,

$643 \quad 90-99$

64455 Janssen, M.A. et al. (2010) Lab Experiments for the Study of Social-Ecological

$645 \quad$ Systems. Science (80-. ). 328, 613-617

64656 Barrett, S. and Dannenberg, A. (2012) Climate negotiations under scientific

647 uncertainty. Proc. Natl. Acad. Sci. U. S. A. 109, 17372-6

64857 Perrotton, A. et al. (2017) My cattle and your park: Codesigning a role-playing

649 game with rural communities to promote multistakeholder dialogue at the

650 edge of protected areas. Ecol. Soc. 22,

65158 Bolton, G.E. and Ockenfels, A. (2000) ERC: A theory of equity, reciprocity, and

652 competition. Am. Econ. Rev. 90, 166-193

65359 Song, Z. et al. (2012) The role of fairness norms the household-based natural

654 forest conservation: The case of Wolong, China. Ecol. Econ. 84, 164-171

65560 Cárdenas, J.C. and Ostrom, E. What do people bring into the game?

656 Experiments in the field about cooperation in the commons. , Agricultural

657 Systems, 82. (2004), 307-326

65861 Aswani, S. et al. (2013) Insights from experimental economics on local

659 cooperation in a small-scale fishery management system. Glob. Environ.

$660 \quad$ Chang. 23, 1402-1409

66162 Janssen, M.A. et al. (2013) Breaking the elected rules in a field experiment on 662 forestry resources. Ecol. Econ. 90, 132-139

66363 Villamor, G.B. and Badmos, B.K. (2016) Grazing game: A learning tool for

664 adaptive management in response to climate variability in semiarid areas of 665 Ghana. Ecol. Soc. 21,

66664 Vieira Pak, M. and Castillo Brieva, D. (2010) Designing and implementing a

667 Role-Playing Game: A tool to explain factors, decision making and landscape

668 transformation. Environ. Model. Softw. 25, 1322-1333

66965 Janssen, M.A. et al. (2015) Advancing the understanding of behavior in social-

670 ecological systems: Results from lab and field experiments. Ecol. Soc. 20, 
67166 Mesterton-Gibbons, M. and Milner-Gulland, E.J. (1998) On the strategic

672 stability of monitoring: implications for cooperative wildlife programmes in

$673 \quad$ Africa. Proc. R. Soc. B Biol. Sci. 265, 1237-1244

67467 KEANE, A. et al. (2012) Modelling the effect of individual strategic behaviour

675 on community-level outcomes of conservation interventions. Environ.

676 Conserv. 39, 305-315

67768 Madani, K. and Lund, J.R. (2011) A Monte-Carlo game theoretic approach for

678 Multi-Criteria Decision Making under uncertainty. Adv. Water Resour. 34,

$679 \quad 607-616$

68069 Cardenas, J.C. et al. (2000) Local environmental control and institutional

681 crowding-out. World Dev. 28, 1719-1733

68270 Travers, H. et al. (2011) Incentives for cooperation: The effects of institutional

683 controls on common pool resource extraction in Cambodia. Ecol. Econ. 71,

$684 \quad 151-161$

68571 Salk, C. et al. Simple Incentives and Group Dependence for Successful

686 Payments for Ecosystem Services Programs: Evidence from an Experimental

687 Game in Rural Lao PDR. , Conservation Letters, 10. (2017) , 413-420

68872 Gatiso, T.T. et al. (2017), If Possible, Incentivize Individuals Not Groups:

689 Evidence from Lab-in-the-Field Experiments on Forest Conservation in Rural

$690 \quad$ Uganda. , Conservation Letters

69173 Worrapimphong, K. et al. (2010) A companion modeling approach applied to

692 fishery management. Environ. Model. Softw. 25, 1334-1344

69374 Camilo Cardenas, J. and Carpenter, J.P. THREE THEMES ON FIELD

694 EXPERIMENTS AND ECONOMIC DEVELOPMENT. , Research in Experimental

$695 \quad$ Economics, 10. (2004), 71-123

69675 García-Barrios, L. et al. (2011) Social dilemmas and individual/group

697 coordination strategies in a complex rural land-use game. Int. J. Commons 5,

$698 \quad 364-387$

69976 Castillo, D. et al. (2011) Context matters to explain field experiments: Results

700 from Colombian and Thai fishing villages. Ecol. Econ. 70, 1609-1620

70177 Fox, A.D. and Madsen, J. (2017) Threatened species to super-abundance: The

702 unexpected international implications of successful goose conservation. 
70478 Tuvendal, M. and Elmberg, J. (2015) A handshake between markets and

705 hierarchies: Geese as an example of successful collaborative management of ecosystem services. Sustain. 7, 15937-15954

70779 Fox, A.D. et al. (2016), Agriculture and herbivorous waterfowl: A review of the 708 scientific basis for improved management. , Biological Reviews

70980 Eythórsson, E. et al. (2017) Goose management schemes to resolve conflicts 710 with agriculture: Theory, practice and effects. Ambio 46, 231-240

71181 Jackson, C. (2012) Internal and External Validity in Experimental Games: A $712 \quad$ Social Reality Check. Eur. J. Dev. Res. 24, 71-88

71382 Guala, F. (2005) The Methodology of Experimental Economics. Cambridge $714 \quad$ Univ. Press DOI: 10.1017/CBO9780511614651

71583 Vohs, K.D. et al. Merely activating the concept of money changes personal and 716 interpersonal behavior. , Current Directions in Psychological Science, 17. $717 \quad$ (2008) , 208-212

71884 Voinov, A. and Bousquet, F. (2010) Modelling with stakeholders. Environ. $719 \quad$ Model. Softw. 25, 1268-1281

72085 Bryman, A. (2012) Social Research Methods, 2nd

72186 Barnaud, C. et al. (2010) Dealing with power games in a companion modelling 722 process: Lessons from community water management in Thailand highlands. J. Agric. Educ. Ext. 16, 55-74

72487 St.John, F.A. V et al. Research ethics: Assuring anonymity at the individual 725 level may not be sufficient to protect research participants from harm. , 726 Biological Conservation, 196. (2016) , 208-209

72788 Madden, F. (2004) Creating Coexistence between Humans \nand Wildlife:

728 Global Perspectives \non Local Efforts to Address \nHuman-Wildlife Conflict. $729 \quad$ Hum. Dimens. WildI. 9, 247-257

73089 Garcia, C.A. et al. (2010) Biodiversity conservation in agricultural landscapes:

731 challenges and opportunities of coffee agroforests in the Western Ghats, $732 \quad$ India. Conserv. Biol. 24, 479-488

73390 Nath, C.D. et al. (2011) Promoting native trees in shade coffee plantations of 734 southern India: Comparison of growth rates with the exotic Grevillea robusta. 

Agrofor. Syst. 83, 107-119

73691 Ambinakudige, S. and Sathish, B.N. (2009) Comparing tree diversity and

737 composition in coffee farms and sacred forests in the western ghats of India. Biodivers. Conserv. 18, 987-1000

73992 Neilson, J. and Pritchard, B. (2009) Value Chain Struggles: Institutions and

740 Governance in the Plantation Districts of South India, 